\title{
Increasing the depth of apatite processing by extracting rare-earth elements
}

\author{
E.S. Lukyantseva, V.V. Sergeev \\ St. Petersburg Mining University, St. Petersburg, Russia
}

\begin{abstract}
Currently, most high-technology productions are impossible without rare-earth elements (REE). The heavy rare-earth elements are of great interest as they have the highest market value and are in demand in the vast majority of knowledge-intensive industries. The main recourse of REE in Russia is apatite ore which is used in the production of fertilizers. As a result of its leaching, about $15-20 \%$ of REE goes to wet-process phosphoric acid. To enhance the depth of apatite processing, it is necessary to develop a technology which will allow obtaining rare-earth elements as by-products. The method of extraction and concentration of REE discussed in this paper was conducted by using the extractant based on di-(2ethylhexyl) phosphoric acid (D2EHPA). The mechanism of extraction was studied, as well as the impact of the extractant concentration, phase ratio and the number of stages on the extraction process.
\end{abstract}

\section{Introduction}

Rare-earth elements (REE) are the strategically essential raw material that has found application in various branches such as catalysts and magnet productions, metallurgy, microelectronics, glass industry, and many others. Among rare-earth elements, metals of the heavy group (gadolinium to lutetium and yttrium) are regarded as the most crucial ones due to their extensive application, low reserves, and difficult separation [1].

The consumption of REE has wildly increased over the last several decades [2]. Consequently, the production volumes of REE have risen as well with a growth rate of more than $47 \%$ only for the period between 2014 and 2018. Global mine production of rare-earth elements in 2019 consisted of 210.000 metric tons (recalculated to oxides), while the share of Russia in the global production was only about $1.3 \%$ even though Russia has the fourthlargest reserves of REE in the world $[3,4]$.

The sustained growth of rare-earths consumption necessitated the search for new technologies. Since Russia imports overwhelming amounts of rare-earth elements in the forms of oxides, metals, and alloys, it is an important issue to increase its output to meet domestic and global demand.

Nowadays, there are several main ways of rare-earth elements extraction and separation: solvent extraction $[5,6]$, sorption $[7,8]$, chemical precipitation $[9,10]$, and electrochemical extraction [11]. Solvent extraction is the most efficient technology owing to its high capacity and fast mass transfer $[12,13]$.

Loparite is considered to be the traditional raw material of rare-earth elements in Russia. On the other hand, apatite ore as the alternative REE source is preferable as it has elevated 
concentrations of heavy and middle groups of REE and near-zero radioactivity due to the lack of radioactive isotopes of thorium and uranium. Nevertheless, although apatite is the main source of rare-earth elements in Russia, they have not been previously extracted on an industrial scale because the total amount of the lanthanides in it does not exceed $1 \%$.

Apatite has been used in the production of fertilizers for several decades. To obtain fertilizers, apatite is leached by acids such as sulphuric, nitric, or hydrochloric. The resulting solutions of phosphoric acid, which are used in the further process without rare-earth elements extraction, contain up to $0.1 \%$ of REE. The described technology offers to add a stage of rare-earth elements obtaining as by-products from these solutions before their further use. Since the described method does not change $\mathrm{P}_{2} \mathrm{O}_{5}$ concentration, phosphoric acid after REE extraction can be effectively used in fertilizer production. Therefore, the introduction of the extraction stage will increase the depth of apatite ore processing by obtaining a valuable product without significant changes in the technological scheme. However, the technology requires additional space and equipment for the regeneration of the extractant so that it can be reused.

\section{Theoretical basics of the process}

\subsection{Study object and research methods}

The decomposition of apatite concentrate with sulfuric acid can be carried by semihydrate or dihydrate methods. In the case of the most widespread dihydrate process, the formation of wet-process phosphoric acid and the precipitation of calcium sulfate dihydrate (phosphogypsum) occur. This reaction can be described by equation 1:

$$
\mathrm{Ca}_{5} \mathrm{~F}\left(\mathrm{PO}_{4}\right)_{3}+5 \mathrm{H}_{2} \mathrm{SO}_{4}+2 \mathrm{H}_{2} \mathrm{O}=3 \mathrm{H}_{3} \mathrm{PO}_{4}+5 \mathrm{CaSO}_{4} \cdot 2 \mathrm{H}_{2} \mathrm{O}+\mathrm{HF} \text {. }
$$

As objects of the present study, a product of apatite concentrate processing was used, namely industrial solutions of phosphoric acid obtained from PAO PhosAgro (The Balakovo Branch of Apatit, Saratov Region, Balakovo District, Russia). The composition of these solutions is shown in Tables 1 and 2.

Table 1. Composition of industrial phosphoric acid solutions (mass. \%).

\begin{tabular}{cccccccc}
\hline REE & $\mathrm{P}_{2} \mathrm{O}_{5}$ & $\mathrm{SO}_{3}$ & $\mathrm{~F}$ & $\mathrm{Al}_{2} \mathrm{O}_{3}$ & $\mathrm{CaO}$ & $\mathrm{Fe}_{2} \mathrm{O}_{3}$ & $\mathrm{SiO}_{2}$ \\
\hline $0.07-0.1$ & $26-28$ & $1.2-1.8$ & $1.4-1.5$ & $0.1-0.4$ & $0.3-0.8$ & $0.3-0.4$ & $0.8-1.1$ \\
\hline
\end{tabular}

Table 2. Relative composition of REE oxides in industrial phosphoric acid solutions.

\begin{tabular}{c|c|c|c|c|c}
\hline REE oxide & $\begin{array}{c}\text { Composition, } \\
\text { rel. \% }\end{array}$ & REE oxide & \multicolumn{2}{c}{$\begin{array}{c}\text { Composition, } \\
\text { rel. \% }\end{array}$} & \multicolumn{2}{c}{ REE oxide } & $\begin{array}{c}\text { Composition, } \\
\text { rel. \% }\end{array}$ \\
\hline $\mathrm{La}_{2} \mathrm{O}_{3}$ & 15.07 & $\mathrm{Sm}_{2} \mathrm{O}_{3}$ & 3.18 & $\mathrm{Dy}_{2} \mathrm{O}_{3}$ & 1.92 \\
\hline $\mathrm{Ce}_{2} \mathrm{O}_{3}$ & 37.54 & $\mathrm{Eu}_{2} \mathrm{O}_{3}$ & 0.96 & $\mathrm{Yb}_{2} \mathrm{O}_{3}$ & 0.51 \\
\hline $\mathrm{Pr}_{2} \mathrm{O}_{3}$ & 4.67 & $\mathrm{Gd}_{2} \mathrm{O}_{3}$ & 3.51 & $\mathrm{Y}_{2} \mathrm{O}_{3}$ & 12.51 \\
\hline $\mathrm{Nd}_{2} \mathrm{O}_{3}$ & 18.34 & $\mathrm{~Tb}_{2} \mathrm{O}_{3}$ & 0.43 & $\mathrm{Er}_{2} \mathrm{O}_{3}$ & 0.88 \\
\hline
\end{tabular}

As a result of apatite leaching, 15-20\% of rare-earth elements go to wet-process phosphoric acid including elements of the highest value: dysprosium, yttrium, ytterbium, and erbium, relative abundances of which recalculated to oxides are $1.92,11.51,0.88$, and 0.51 $\%$, respectively. The industrial solid waste of this process, phosphogypsum, contains 80 $85 \%$ of rare-earth elements, mostly light and middle groups [14]. Despite this distribution, wet-process phosphoric acid is more economically attractive, as it does not require preliminary preparation for usage [15]. 
The presence of a large number of different salts in apatite processing products, as well as similar physical and chemical properties of rare-earth elements, make it difficult to extract and separate them into individual components. Their low concentration in comparison with impurity compounds also plays an important role: while the content of lanthanides is $0.07-0.10 \%$, the contents of iron (III) and calcium are 0.3-0.4 and 0.3-0.8\% (recalculated to oxides).

To describe the general tendencies of REE extraction, simulated solutions were also used. Simulated solutions contained $4.5 \mathrm{~mol} / \mathrm{L} \mathrm{H}_{3} \mathrm{PO}_{4}$ and $0.19 \mathrm{~mol} / \mathrm{L} \mathrm{H}_{2} \mathrm{SO}_{4}$ and were prepared by using concentrated (87\%) phosphoric acid from OOO Komponent-Reactiv, Moscow, Russia, and $6 \mathrm{~mol} / \mathrm{L}$ solutions of sulphuric acid. To achieve the required concentrations of rare-earth elements, their nitrates were used (grade "chemically pure").

Since apatite concentrate and hence industrial phosphoric acid solutions are characterized by extremely low amounts of REE, the extraction is the main method for their effective concentration and separation from complex solutions with low $\mathrm{pH}$ values.

Physical-chemical and chemical analysis methods were used to evaluate the data. The composition of aqueous solutions and organic media was analyzed using infrared spectroscopy and X-ray fluorescence spectroscopy. The process parameters such as temperature, phase contact time, and the stirring speed were kept constant in a series of experiments.

\subsection{Selection of the extractant}

Taking into account the specifics of industrial solutions of wet-process phosphoric acid, the extractant should have certain properties that ensure the selective extraction of metals. At the same time, it should not change the composition of phosphoric acid for its further processing.

The most affordable extractants are carboxylic acids such as naphthenic and oleic acids which are easily regenerated and almost insoluble in aqueous solutions. However, carboxylic acids are not selective enough to use them industrially.

Furthermore, crown ethers are widely used in REE extraction. These extractants form the strongest bonds with cations the size of which corresponds to the cavity of the crown ethers. Their high selectivity can be achieved by changing the glycol chain numbers and introducing substituents to their structure. Such operations limit the availability of crown ethers as extractants for REE on a commercial scale [16]. Besides, there is data about their poor effectiveness in acidic solutions with low $\mathrm{pH}$ values [17].

Presently, promising extractants are amides and ionic liquids. However, it has been noted that when used in a strongly acidic medium, they are also less effective since the extraction deteriorates significantly with acidity increasing $[18,19]$.

Solid extractants and sorbents, which are also actively used for REE extraction, are inferior to liquid extractants when it comes to ease of the process implementation and selectivity $[20,21]$.

For systems with high acidity and complex composition, neutral and acidic organophosphorus extractants are the most appropriate: D2EHPA, Tributyl phosphate, Cyanex 272, Cyanex 302. Cyanex 923, PC 88A [22,23]. The highest extraction efficiency can be achieved by using D2EHPA that is selective to the most valuable heavy REE [24,25], and has poor solubility in aqueous solutions [26]. Kerosene was chosen as an inert diluent to reduce the viscosity of the extractant and accelerate the phase separation due to its availability and inertia in relation to solutions with low $\mathrm{pH}$.

Di-(2-ethylhexyl) phosphoric acid used in the study was obtained from ZAO Acrus, Moscow, Russia, with D2EHPA concentration of at least 95\%. Kerosene with a mass fraction of saturated hydrocarbons of at least 95\% (grade "pure") was obtained from OOO Komponent-Reactiv, Moscow, Russia. 


\subsection{The extraction mechanism}

According to known data, D2EHPA extracts rare-earth metals by cation-exchange mechanism $[13,24]$. However, since the extractant's phosphoryl group $\mathrm{P}=\mathrm{O}$ is polar and oxygen is an electron donor, D2EHPA forms also donor-acceptor bonds with REE and the solvation of acid's molecules occurs. Taking into consideration that in phosphoric acid solutions REE form dihydrogenphosphate complexes, the following equation (2) was proposed to describe the extraction process [27]:

$$
\operatorname{Ln}\left(\mathrm{H}_{2} \mathrm{PO}_{4}\right)^{2+}+\left(\frac{2+S}{\mathrm{~S}}\right)(\mathrm{HR})_{2}=\operatorname{Ln}\left(\mathrm{H}_{2} \mathrm{PO}_{4}\right) \mathrm{R}_{2} \cdot(\mathrm{HR})_{\mathrm{S}}+\mathrm{H}^{+},
$$

where $S$ is the number of acid's solvating molecules; $\operatorname{Ln}\left(\mathrm{H}_{2} \mathrm{PO}_{4}\right)^{2+}$ is complex REE ions (III).

Infrared spectroscopy was used to confirm the correctness of the equation (Fig. 1). Analysis of IR spectra of D2EHPA before and after extraction showed a shift of the absorption band from $1227 \mathrm{~cm}^{-1}$, which is distinctive for the phosphoryl group, to $1204 \mathrm{~cm}^{-1}$ due to the extractant's interaction with REE ions. In addition, a wavenumber of $1100 \mathrm{~cm}^{-1}$ was detected in the IR spectrum that characterizes the stretching vibrations of the $\left(\mathrm{H}_{2} \mathrm{PO}_{4}\right)^{-}$ group in the extractant's organic phase. The stoichiometric ratio of ions in the organic phase as $\mathrm{Ln}^{3+}: \mathrm{H}_{2} \mathrm{PO}_{4}{ }^{2+}=1: 1$ was confirmed by the results of $\mathrm{X}$-ray fluorescence analysis.

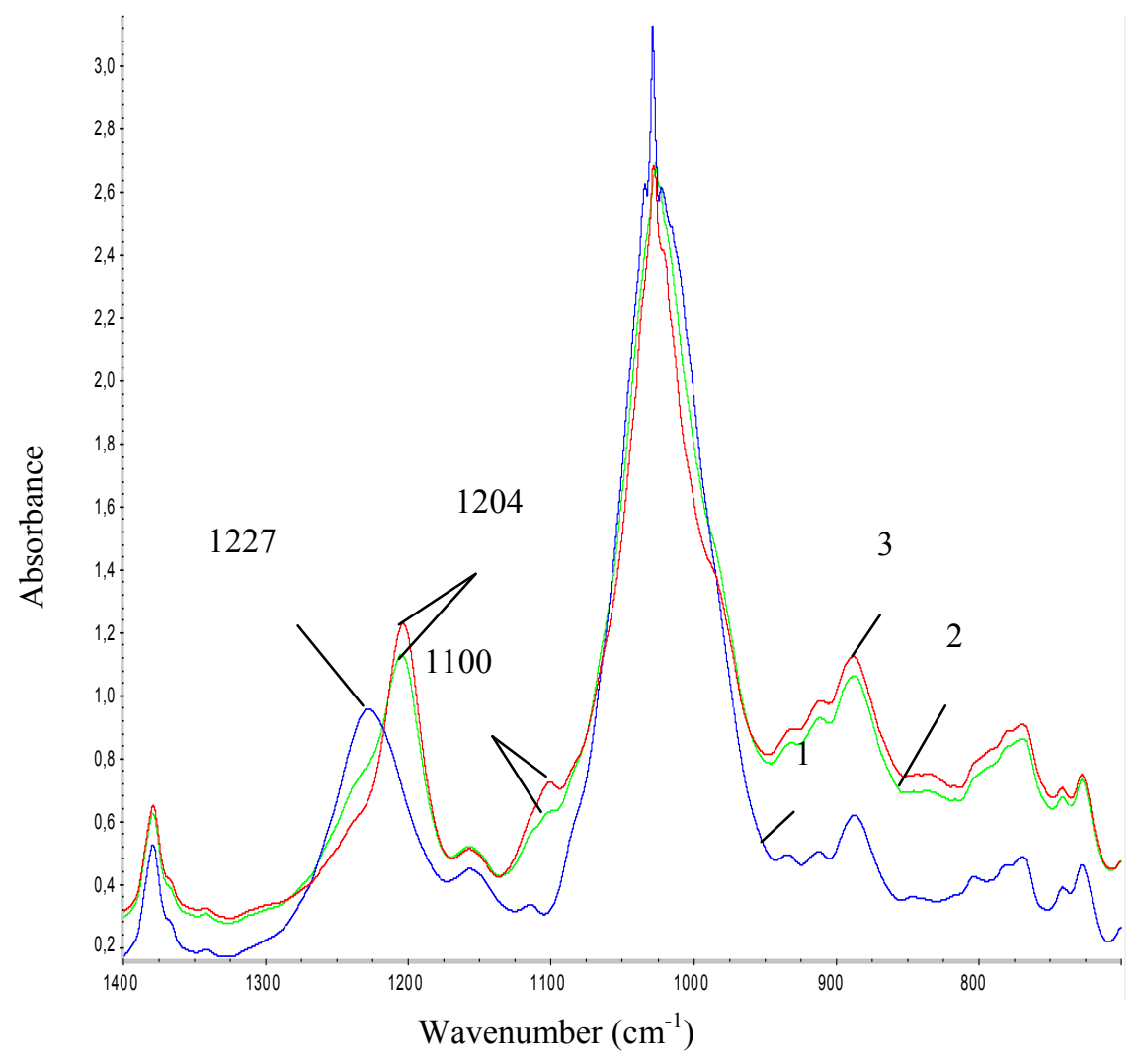

Fig. 1. IR spectra of D2EHPA and organic complexes of REE with D2EHPA, where 1 is the organic phase before extraction; 2 is the organic phase after extraction of $Y ; 3$ is the organic phase after extraction of Er. 
According to the law of mass action, the equilibrium constant can be defined as:

$$
K=\frac{\left[\operatorname{Ln}\left(\mathrm{H}_{2} \mathrm{PO}_{4}\right) R_{2} \cdot(\mathrm{HR})_{S}\right] \cdot\left[\mathrm{H}^{+}\right]^{2} \cdot \gamma_{H^{+}}^{2}}{\left[\operatorname{Ln}\left(\mathrm{H}_{2} \mathrm{PO}_{4}\right)^{2+}\right] \cdot \gamma_{\left(\operatorname{Ln}\left(\mathrm{H}_{2} \mathrm{PO}_{4}\right)\right)^{2+}} \cdot\left[(\mathrm{HR})_{2}\right]^{\left.\frac{(2+S}{2}\right)}},
$$

or

$$
\ln K=\ln D+2 \ln a_{H^{+}}-\ln \gamma_{\left(\operatorname{Ln}\left(\mathrm{H}_{2} P O_{4}\right)\right)^{2+}}-\left(\frac{2+S}{2}\right) \ln \left[(H R)_{2}\right],
$$

where $\mathrm{D}$ is the distribution coefficient; $a_{H^{+}}$is the activity of hydrogen ions;

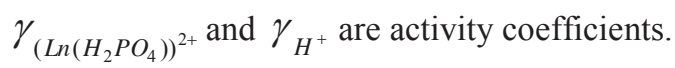

For phosphoric solutions with ionic strength $\mathrm{I}=0-2.5 \mathrm{~mol} / \mathrm{kg}, \gamma_{\left(\operatorname{Ln}\left(\mathrm{H}_{2} \mathrm{PO}_{4}\right)\right)^{2+}}$ can be calculated as follows (Lebedev 1978):

To find out the number of solvates of organic complexes, the dependence of the distribution coefficient on the molar fraction of the extractant was studied (Fig. 2). The angular coefficient of each metal corresponds with the solvate number in the extracted complex of this metal. The results of the calculation of solvate numbers are shown in Table 3.

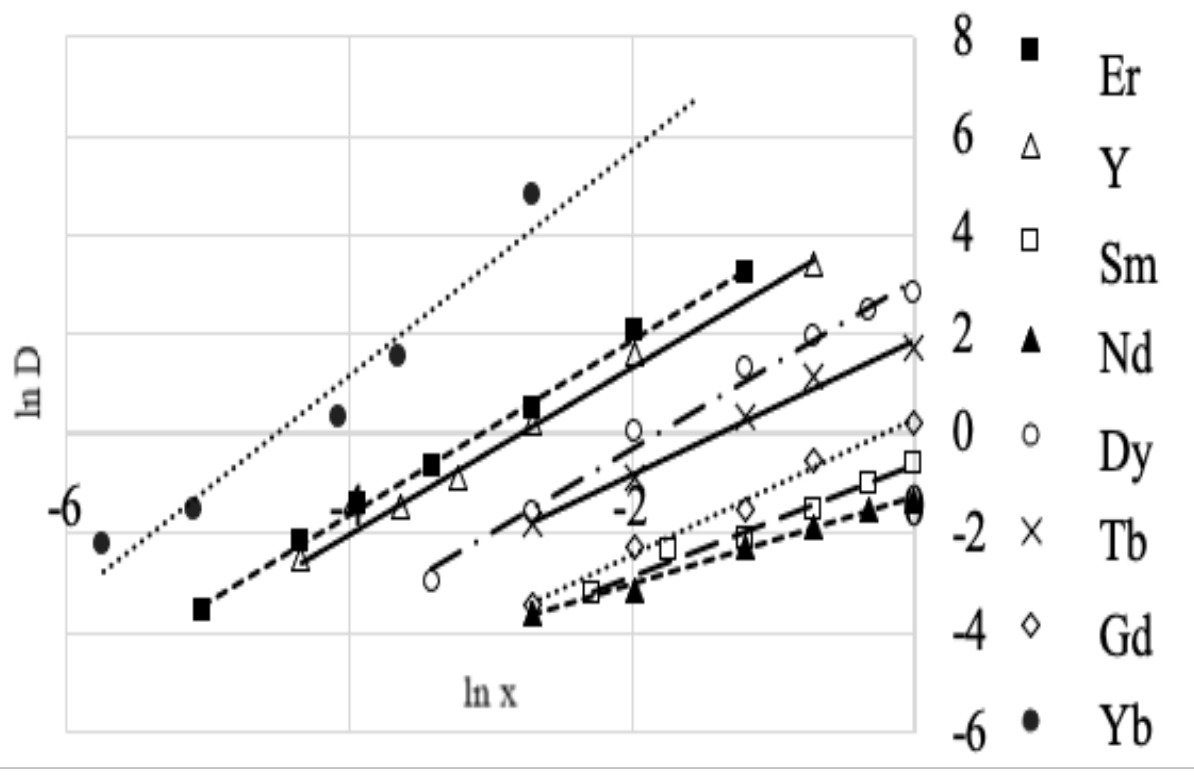

Fig. 2. Dependence of the logarithm of the distribution coefficient of REE on the logarithm of the D2EHPA molar fraction.

\begin{tabular}{|c|c|c|c|}
\hline $\begin{array}{c}\mathrm{RE} \\
\mathrm{E}\end{array}$ & $\begin{array}{c}\text { Approximation } \\
\text { equations }\end{array}$ & $\begin{array}{c}\text { Sol- } \\
\text { vent } \\
\text { num- } \\
\text { ber } \\
(2+\mathrm{S})\end{array}$ & Equations of the extraction equilibrium \\
\hline $\mathrm{Nd}$ & $\ln D=0.87 \cdot \ln x-1.27$ & 2 & $\mathrm{Nd}\left(\mathrm{H}_{2} \mathrm{PO}_{4}\right)^{2+}+(\mathrm{HR})_{2}=\mathrm{Nd}\left(\mathrm{H}_{2} \mathrm{PO}_{4}\right) \mathrm{R}_{2}+2 \mathrm{H}^{+}$ \\
\hline $\mathrm{Sm}$ & $\ln D=1.10 \cdot \ln x-0.62$ & 3 & $\mathrm{Sm}\left(\mathrm{H}_{2} \mathrm{PO}_{4}\right)^{2+}+1.5(\mathrm{HR})_{2}=\mathrm{Sm}\left(\mathrm{H}_{2} \mathrm{PO}_{4}\right) \mathrm{R}_{2}(\mathrm{HR})+2$ \\
\hline
\end{tabular}

Table 3. Equations of the extraction equilibrium. 


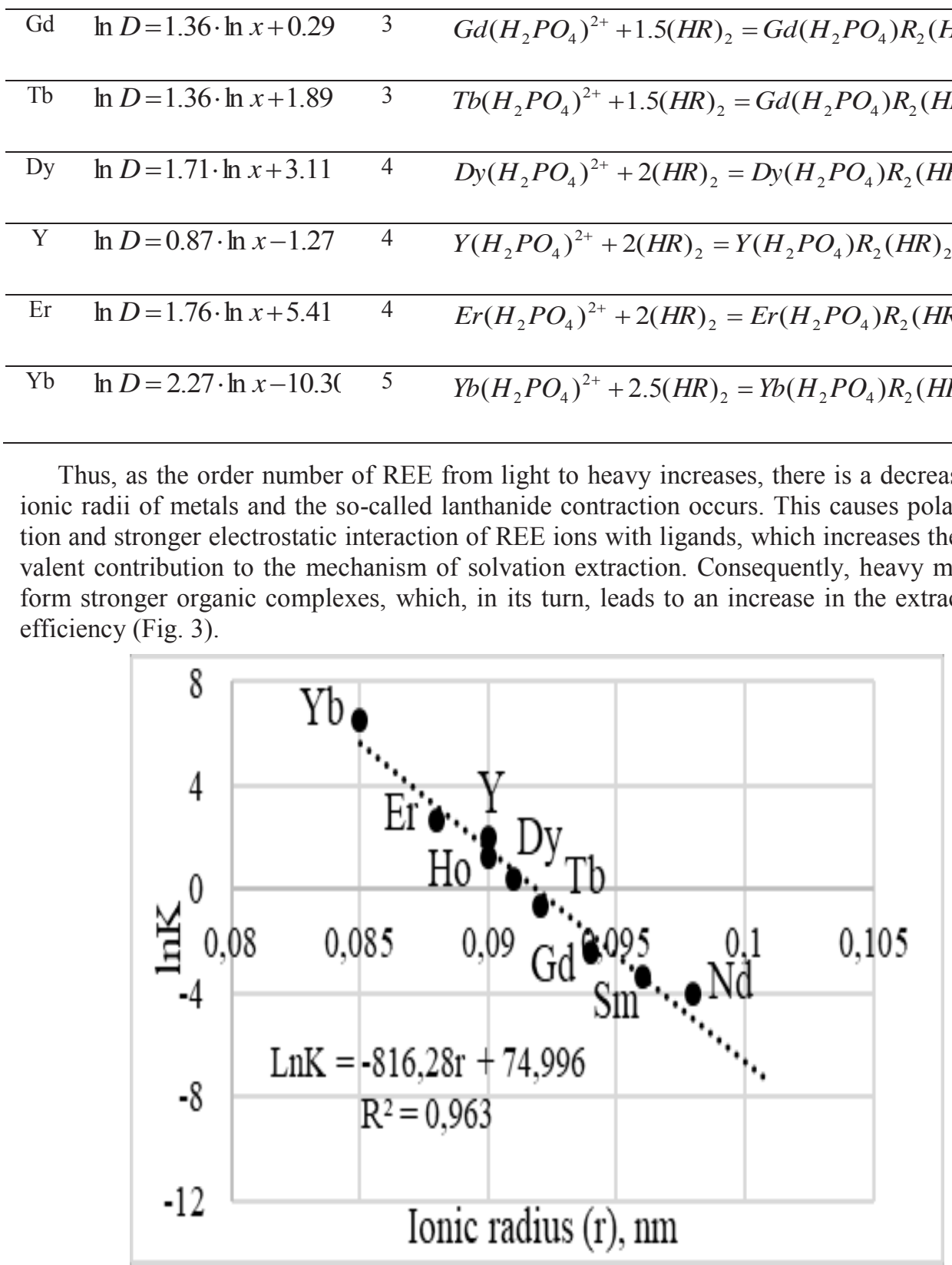

Fig. 3. Dependence of extractability on the ionic radius.

The different stability of the extracted complexes was also confirmed by Gibbs energies calculations as follows:

$$
\Delta_{r} G_{298}^{0}=-R T \ln K,
$$

where $\mathrm{R}$ is the universal gas constant; $\mathrm{T}$ is the absolute temperature $(298,15 \mathrm{~K})$; $\mathrm{K}$ is the extraction constant. 
Calculated standard Gibbs energies for REE that were explored in this paper are presented in Table 4.

Table 4. Gibbs energies of extracted REE complexes, $\mathrm{kJ} / \mathrm{mol}$.

\begin{tabular}{cccc}
\hline $\mathrm{Yb}\left(\mathrm{H}_{2} \mathrm{PO}_{4}\right)^{2+}$ & $\mathrm{Er}\left(\mathrm{H}_{2} \mathrm{PO}_{4}\right)^{2+}$ & $\mathrm{Y}_{(}\left(\mathrm{H}_{2} \mathrm{PO}_{4}\right)^{2+}$ & $\mathrm{Dy}\left(\mathrm{H}_{2} \mathrm{PO}_{4}\right)^{2+}$ \\
\hline$-14.41 \pm 0.29$ & $-6.49 \pm 0.19$ & $-4.77 \pm 0.09$ & $-0.91 \pm 0.05$ \\
\hline
\end{tabular}

It has been also established that an organic phase with a low concentration of D2EHPA in it mainly extracts elements with the smallest radii, which are heavy REE (Table 5). These metals have the greatest practical value, therefore, further work was continued with them.

Table 5. Extraction of REE from wet-process phosphoric acid by the extractant with 30\% D2EHPA.

\begin{tabular}{ccccc}
\hline \multicolumn{5}{c}{ Extraction efficiency, \% } \\
\hline $\mathrm{Yb}$ & $\mathrm{Er}$ & $\mathrm{Y}$ & $\mathrm{Dy}$ & Other REE \\
\hline 99 & 95 & 90 & 65 & $<10$ \\
\hline
\end{tabular}

The effect of D2EHPA concentration on the extraction process was studied. The results are shown in Figure 4.

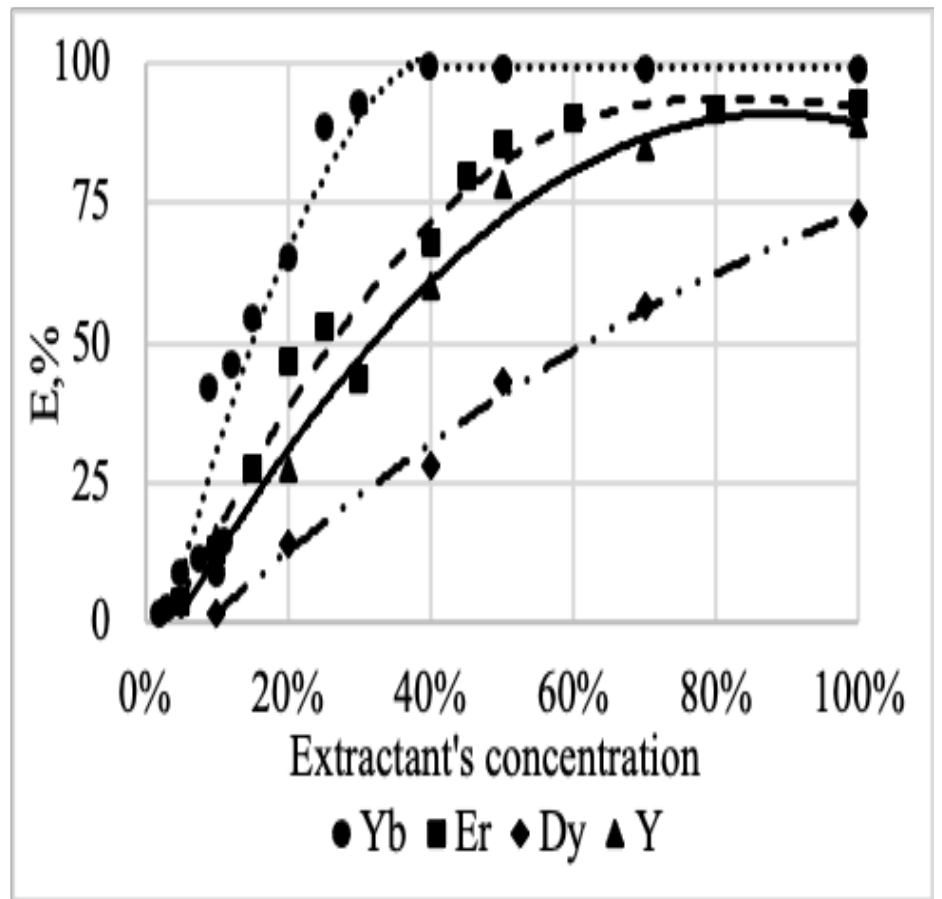

Fig. 4. Dependence of extraction efficiency on extractant's concentration.

According to the graph, to achieve a high extraction efficiency (E, \%) of ytterbium, it is enough to use D2EHPA in the extractant of $30-40 \%$, while for other metals, the extractant with a higher concentration is required. 
To evaluate the effectiveness of the organic solvent, solutions of phosphoric acid after apatite processing and solutions simulating its composition were used. As can be seen in Figure 5, when extracting REE from apatite leaching product, the extraction degree is 10$15 \%$ lower compared to extraction from simulated solutions. It can be explained by a large number of impurities in wet-process phosphoric acid, such as titanium and iron, the content of which in the feedstock is several times higher than the total REE content.

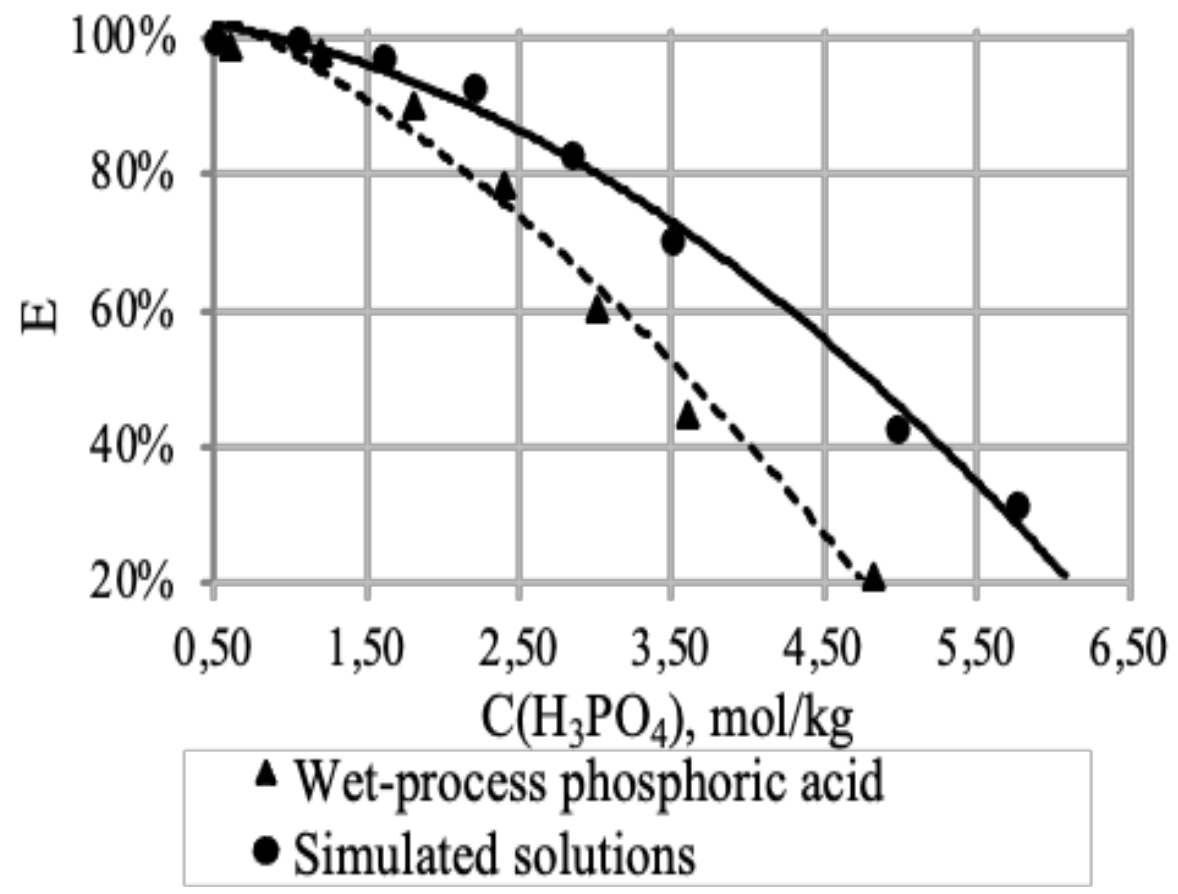

Fig. 5. Dependence of extraction efficiency on a concentration of phosphoric acid.

\section{Concentration and separation of ree}

\subsection{Effect of phase ratio on the extraction process}

In further experiments, two simulated solutions were made. A solution with the same content of metals, namely ytterbium, erbium, yttrium, and dysprosium, was used to study the general patterns of REE extraction, while a solution with metals content close to their content in industrial solutions of phosphoric acid was used to determine the effect of each metal concentration on the extraction. Based on the obtained data that a low concentration of D2EHPA is sufficient to extract ytterbium; the experiment was conducted by using the extractant with $30 \%$ of D2EHPA.

It was found that with the first solution, the extraction efficiency goes down sharply in case of an increasing aqueous-to-organic phase ratio due to a significant decrease of REE distribution coefficients (Table 6, Fig. 6). The extraction efficiency of ytterbium is much better, as it forms a stronger extractable complex. 
Table 6. The results of extraction from the solution with the same REE content.

\begin{tabular}{lcccccccc}
\hline \multirow{2}{*}{$\mathrm{V}_{\mathrm{aq}} / \mathrm{V}_{\text {org }}$} & \multicolumn{2}{c}{$\mathrm{Yb}$} & \multicolumn{2}{c}{$\mathrm{Y}$} & \multicolumn{2}{c}{$\mathrm{Er}$} & \multicolumn{3}{c}{$\mathrm{Dy}$} \\
\cline { 2 - 10 } & $\mathrm{D}$ & $\mathrm{E}, \%$ & $\mathrm{D}$ & $\mathrm{E}, \%$ & $\mathrm{D}$ & $\mathrm{E}, \%$ & $\mathrm{D}$ & $\mathrm{E}, \%$ \\
\hline 20 & 6.90 & 25.64 & 0.32 & 1.55 & 0.50 & 2.44 & 0.45 & 2.19 \\
10 & 13.98 & 58.30 & 0.93 & 8.48 & 1.57 & 13.56 & 0.50 & 4.76 \\
5 & 83.65 & 94.36 & 1.32 & 20.84 & 2.46 & 32.96 & 0.43 & 7.96 \\
2 & 398.00 & 99.50 & 1.19 & 37.40 & 1.74 & 46.50 & 0.27 & 11.70 \\
\hline
\end{tabular}

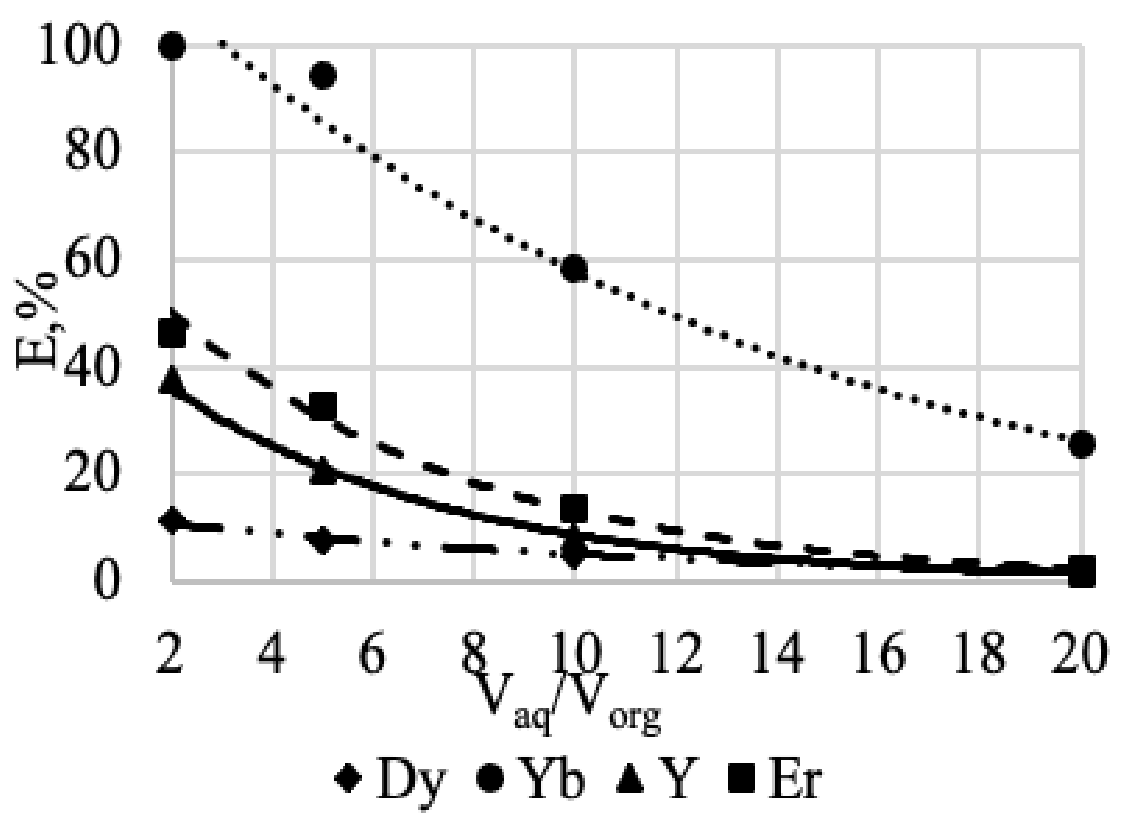

Fig. 6. Dependence of extraction efficiency on phase ratio.

When extracted from the solution with REE content close to its content in industrial solutions, the behavior is similar (Table 7, Fig. 7). The average separation factors of metals take the following values: $\mathrm{Yb} / \mathrm{Y}=8, \mathrm{Y} / \mathrm{Er}=4, \mathrm{Er} / \mathrm{Dy}=4$. In joint presence, the results of extraction deteriorate, which is explained by the competitive participation of elements. Thus, even though the content of yttrium is an order of magnitude higher than the content of other metals, ytterbium displaces it and compounds of other metals.

Table 7. The results of extraction from the solution with the content of REE close to industrial solutions.

\begin{tabular}{lcccccccc}
\hline \multirow{2}{*}{$\mathrm{V}_{\text {aq }} / \mathrm{V}_{\text {org }}$} & \multicolumn{2}{c}{$\mathrm{Yb}$} & \multicolumn{2}{c}{$\mathrm{Y}$} & \multicolumn{2}{c}{$\mathrm{Er}$} & \multicolumn{3}{c}{$\mathrm{Dy}$} \\
\cline { 2 - 9 } & $\mathrm{D}$ & $\mathrm{E}, \%$ & $\mathrm{D}$ & $\mathrm{E}, \%$ & $\mathrm{D}$ & $\mathrm{E}, \%$ & $\mathrm{D}$ & $\mathrm{E}, \%$ \\
\hline 20 & 6.09 & 23.33 & 0.84 & 4.01 & 0.17 & 0.86 & 0.07 & 0.35 \\
10 & 8.07 & 44.67 & 0.87 & 8.04 & 0.32 & 3.14 & 0.06 & 0.60 \\
5 & 8.64 & 81.20 & 0.95 & 15.92 & 0.24 & 4.57 & 0.05 & 0.90 \\
2 & 9.19 & 91.41 & 1.10 & 21.23 & 0.25 & 6.51 & 0.05 & 1.12 \\
\hline
\end{tabular}




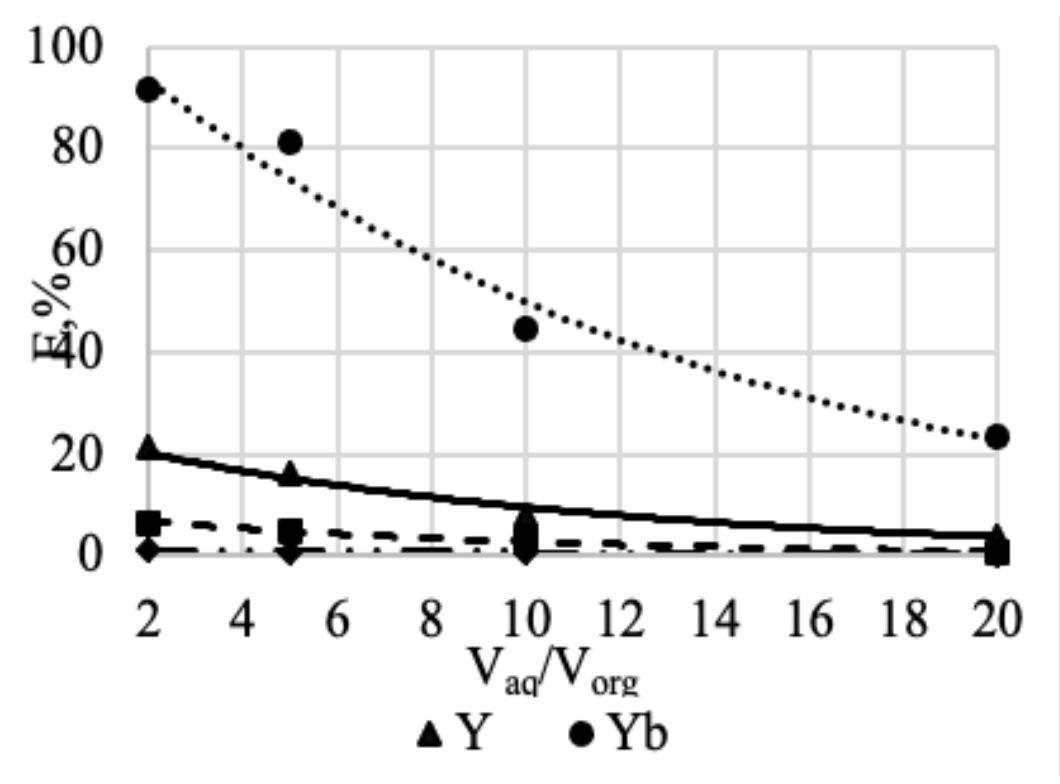

Fig. 7. Dependence of extraction efficiency on phase ratio.

\subsection{Effect of the number of stages on the extraction process}

The next step was to study the dependence of the extraction on the number of stages. The same simulated solutions were used. Each step of multi-stage batch extraction was conducted with a new portion of the initial aqueous solution to saturate the organic phase by REE. The results are presented in Tables 8-9 and Figure 8.

Table 8. The results of extraction from the solution with the same REE content.

\begin{tabular}{lcccccc}
\hline \multirow{2}{*}{ Stage } & \multicolumn{3}{c}{$\mathrm{D}$} & \multicolumn{3}{c}{$\mathrm{E}, \%$} \\
\cline { 2 - 7 } & $\mathrm{Yb}$ & $\mathrm{Y}$ & $\mathrm{Dy}$ & $\mathrm{Yb}$ & $\mathrm{Y}$ & $\mathrm{Dy}$ \\
\hline 1 & 3.33 & 0.56 & 0.24 & 39.97 & 10.06 & 4.57 \\
2 & 3.24 & 0.36 & 0.17 & 39.32 & 6.69 & 3.30 \\
3 & 2.52 & 0.06 & 0.10 & 33.55 & 1.14 & 2.03 \\
4 & 1.87 & 0.13 & 0.08 & 27.19 & 2.48 & 1.59 \\
\hline
\end{tabular}

Table 9. The results of extraction from the solution with the content of REE close to industrial solutions.

\begin{tabular}{ccccccc}
\hline \multirow{2}{*}{ Stage } & \multicolumn{3}{c}{$\mathrm{D}$} & \multicolumn{3}{c}{ E, \% } \\
\cline { 2 - 7 } & $\mathrm{Yb}$ & $\mathrm{Y}$ & $\mathrm{Dy}$ & $\mathrm{Yb}$ & $\mathrm{Y}$ & $\mathrm{Dy}$ \\
\hline 1 & 3.82 & 0.91 & 0.10 & 43.33 & 15.43 & 1.90 \\
2 & 8.89 & 0.28 & 0.07 & 54.00 & 5.37 & 1.40 \\
3 & 5.42 & 0.27 & 0.05 & 52.00 & 5.11 & 0.90 \\
4 & 4.74 & 0.13 & 0.04 & 48.67 & 2.52 & 0.80 \\
5 & 4.15 & 0.12 & 0.05 & 45.33 & 2.37 & 0.90 \\
\hline
\end{tabular}




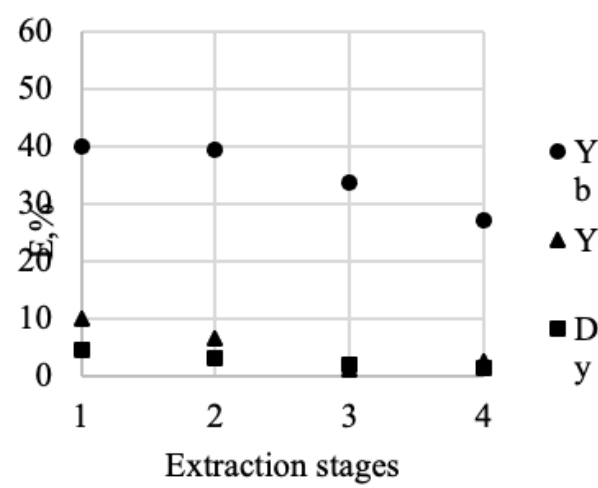

a)

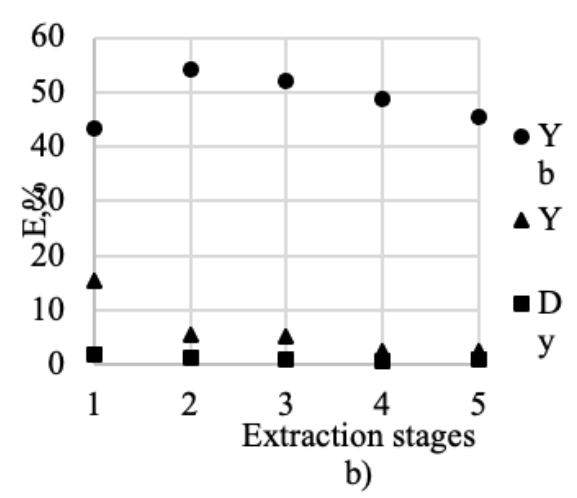

b)

Fig. 8. Dependence of extraction efficiency on the number of stages: a) from the solution with the same REE content, b) from the solution with the content of REE close to industrial solutions.

When performing a multi-stage extraction, there is a drop of extraction degree, which can be explained by the gradual saturation of the organic phase and the shift of the equilibrium towards the side of reactants. Nevertheless, in the case of extraction from the solution with REE content close to industrial, the extraction efficiency of ytterbium either increases or remains unchanged due to the displacement of dysprosium and yttrium. Thus, ytterbium's ability to form a stronger extractable complex with D2EHPA leads to its concentration in the organic phase while its percentage content grows (Fig. 9). The extraction efficiency of dysprosium, in its turn, decreases sharply, as well as the extraction efficiency of yttrium, despite its high concentration in wet-process phosphoric acid. As a result, the separation factors increase from stage to stage, and for the pair of ytterbium/yttrium, the factor rises from 5 to 36 after five stages.

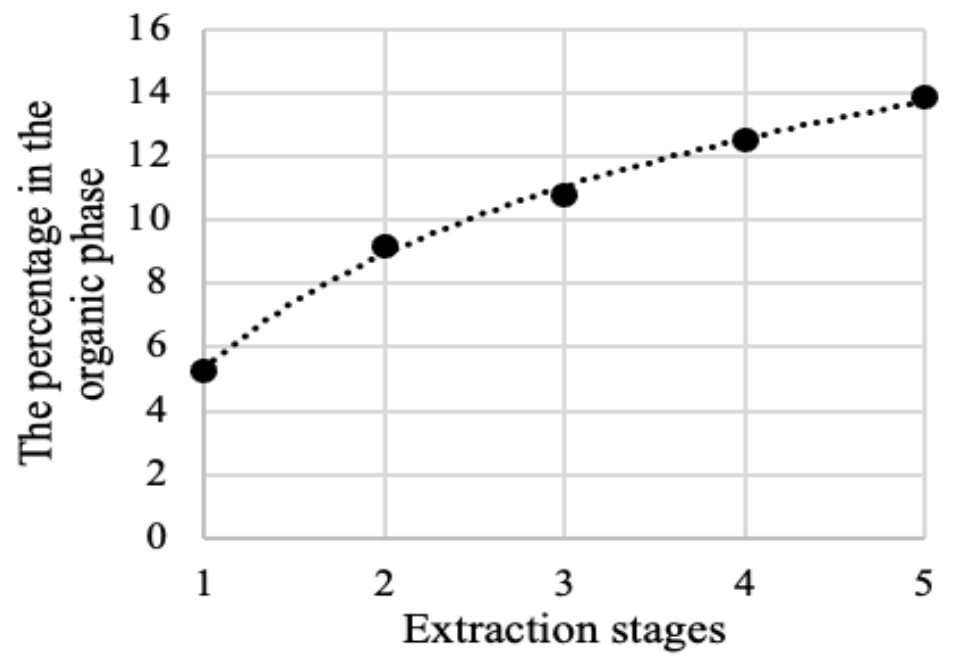

Fig. 9. The percentage of ytterbium depending on the number of stages.

In terms of using the extractant with $30 \%$ of D2EHPA, the extraction efficiency of dysprosium to the organic phase tends to zero, so it is advisable to extract it by a solvent with a higher concentration of the extractant. Thus, extraction was carried by D2EHPA of $70 \%$. The obtained data are shown in Table 10 and Figure 10 . With increasing the volume of the aqueous phase, both the extraction efficiency and distribution coefficient fall dramatically. There is no practical use in a phase ratio greater than $\mathrm{V}_{\mathrm{aq}} / \mathrm{V}_{\text {org }}=5$ since the extraction efficiency will be less than $30 \%$ per stage in this case. 
Table 10. The results of dysprosium extraction.

\begin{tabular}{lcc}
\hline $\mathrm{V}_{\mathrm{aq}} / \mathrm{V}_{\text {org }}$ & $\mathrm{D}$ & $\mathrm{E}, \%$ \\
\hline 2 & 2.59 & 56.46 \\
5 & 2.27 & 31.22 \\
10 & 1.35 & 11.89 \\
20 & 1.57 & 7.26 \\
\hline
\end{tabular}

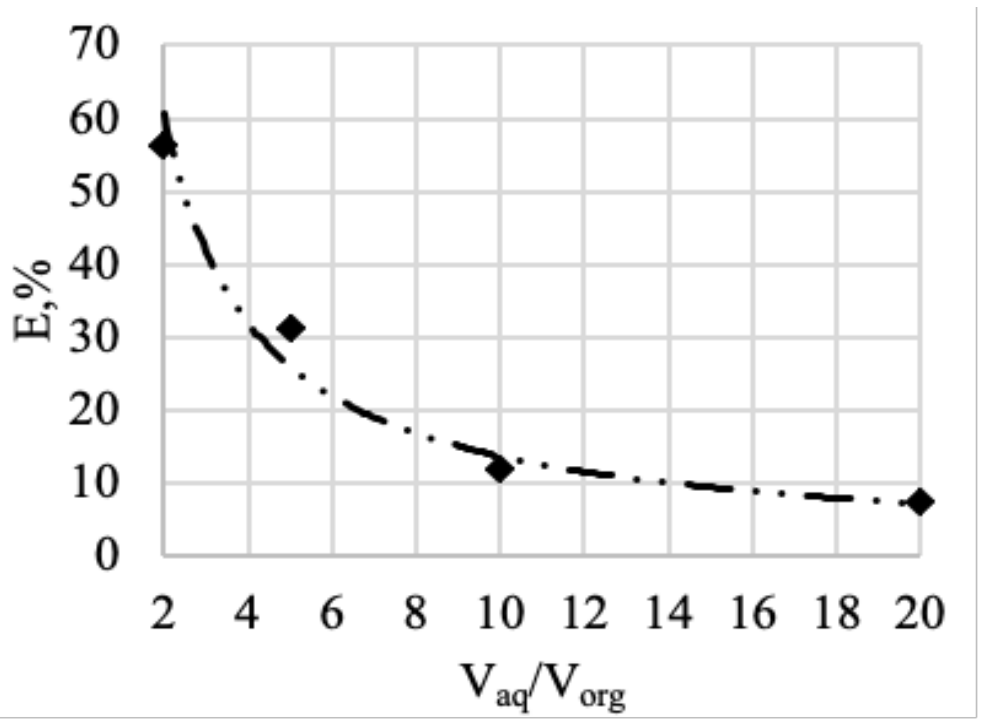

Fig. 10. Dependence of extraction efficiency of dysprosium on phase ratio.

To purify the extract from iron and titan during the extraction process, as well as after it, there should be a stripping stage for which oxalic acid can be used. A fuller separation of rare-earth elements can be achieved at the stage of re-extraction by sulfuric acid with subsequent precipitation of REE by sodium carbonate [28].

\subsection{The extractant capacity}

The saturation of the organic phase by ytterbium is limited by the extractant capacity, which was determined by multi-stage countercurrent extraction using a cascade of extractors. The results can be seen in Figure 11. It was found that the capacity of D2EHPA for ytterbium takes the value of $45 \mathrm{mM}$ which exceeds its concentration in wet-process phosphoric acid by several orders of magnitude. 


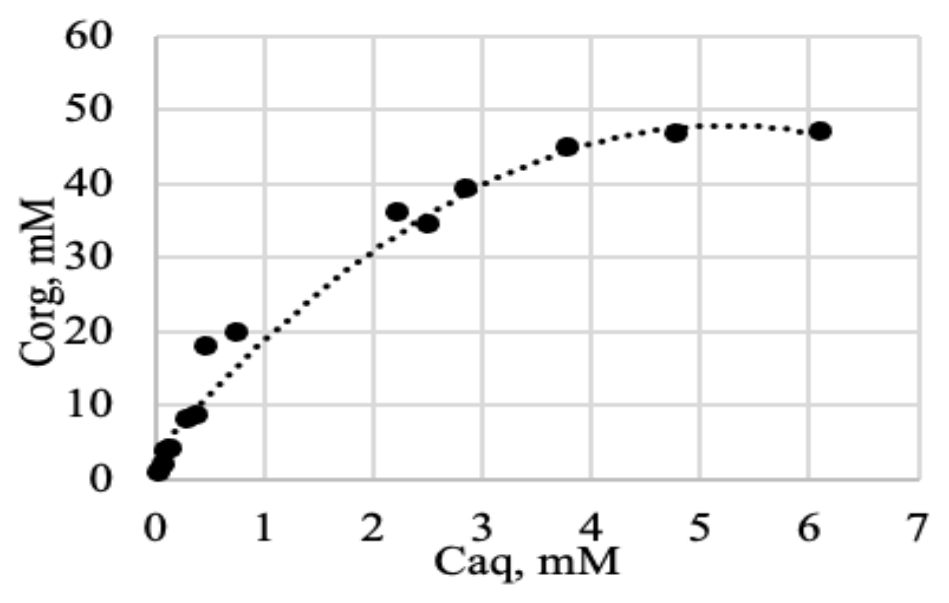

Fig. 11. D2EHPA's capacity for ytterbium.

\section{Conclusions}

In the course of the research, the equation describing the extraction mechanism by di-(2ethylhexyl) phosphoric acid was derived. It has been established that the extraction efficiency rises with a decrease in the radius of metals due to the formation of more stable extractable complexes with the extractant.

It was found that the usage of different concentrations of D2EHPA in the solvent provides selective extraction of rare-earth elements. Thus, the highest extraction degree of ytterbium and yttrium was achieved at the phase ratio $\mathrm{V}_{\mathrm{aq}} / \mathrm{V}_{\text {org }}=10$ using D2EHPA with a molar fraction of 0.3 for ytterbium and 0.7 for yttrium. The obtained average REE separation factors were as follows: $\mathrm{Yb} / \mathrm{Y}=8, \mathrm{Y} / \mathrm{Er}=4, \mathrm{Er} / \mathrm{Dy}=4$.

Though dysprosium has the least effective extraction results, it is possible to achieve the extraction efficiency of more than $90 \%$ by increasing the volume of the organic phase to phase ratio $\mathrm{V}_{\mathrm{aq}} / \mathrm{V}_{\text {org }}=2$ and performing three stages of extraction. If the phase ratio is $\mathrm{V}_{\mathrm{aq}} / \mathrm{V}_{\text {org }}=5$, six stages are required.

The saturation of the organic phase for ytterbium is limited by extractant capacity, which is $45 \mathrm{mM}$ according to the study.

This paper was supported by the Russian Science Foundation as part of project No. 19-19-00377.

\section{References}

1. X. Du, T.E. Graedel,. Global In-Use Stocks of the Rare Earth Elements: A First Estimate. Environmental Science \& Technology 45(9). 4096-4101 (2011)

2. A.A. Gasanov, A.V. Naumov, O.V. Yurasova, I.M. Petrov, T.E. Litvinova, Certain tendencies in the Rare-Earth-Element world market and prospects of Russia. Russian Journal of Non-Ferrous Metals 59, 502-511 (2018)

3. World Mining Data, Minerals Production, 35: 51 (2020)

4. U.S. Geological Survey, Mineral commodity summaries, 132-133, (2020)

5. M. Gergoric, C. Ekberg, B.M. Steenari, T. Retegan, T. Separation of Heavy Rare-Earth Elements from Light Rare-Earth Elements Via Solvent Extraction from a Neodymium Magnet Leachate and the Effects of Diluents. Journal of Sustainable Metallurgy, 3, : 601-610 (2017) 
6. J.E. Quinn, K.H. Soldenhoff, G.W. Stevens, Solvent extraction of rare earth elements using a bifunctional ionic liquid. Part 2: Separation of rare earth elements. Hydrometallurgy ,169, 621-628 (2017)

7. S Yulusov, T.Y. Surkova, , L.U. Amanzholova, M.B. Barmenshinova, On sorption of the rare-earth elements. Journal of Chemical Technology and Metallurgy, 53(1), 79-82 (2018)

8. H. Liu, O. Pourret, H. Guo, J. Bonhoure, Rare earth elements sorption to iron oxyhydroxide: Model development and application to groundwater. Applied Geochemistry, 87, 158-166 (2017)

9. S.M. Xaba, M. Nete, W. Purcell, Concentration of rare earth elements from monazite by selective precipitation. IOP Conference Series Materials Science and Engineering, 430(1), 012006 (2018)

10. H. Huang, X. Xiao, L. Yang, B. Yan, Removal of ammonia nitrogen from washing wastewater resulting from the process of rare-earth elements precipitation by the formation of struvite. Desalination and Water Treatment, 24(1-3), 85-92 (2010)

11. S. Maes, W.Q. Zhuang, K. Rabaey, L. Alvarez-Cohen, T. Hennebel, Concomitant Leaching and Electrochemical Extraction of Rare Earth Elements from Monazite. Environmental Science \& Technology 51(3):1654-1661 (2017).

12. D. Li, A review on yttrium solvent extraction chemistry and separation process. Journal of Rare Earths 35(2): 107-119 (2017).

13. F Xie, T.A. Zhang, D.B. Dreisinger, F.M. Doyle, A critical review on solvent extraction of rare earths from aqueous solutions. Minerals Engineering 56: 10-28 (2014).

14. I. Hammas-Nasri, K. Horchani-Naifer, M. Férid, D. Barca, Rare-earths concentration from phosphogypsum waste by two-step leaching method. International Journal of Mineral Processing 149: 78-83 (2016).

15. D. Lutskiy, T. Litvinova, A. Ignatovich, I. Fialkovskiy, Complex processing of phosphogypsum - A way of recycling dumps with reception of commodity production of wide application. Journal of Ecological Engineering 19(2): 223-227 (2018).

16. Kurysheva, V.V. Ivanova, E.V., Prohorova, P.E. 2016. Extractant for rare earth metals. Chimica Techno Acta 3(2): 97-120.

17. S.V. Demin, V.I. Zhilov, A. Yu. Tsivadze, V.V. Yakshin, O.N. Vilkova, N.A. Tsarenko, Extraction of rare-earth elements by alkylated dibenzo-18-crown- 6 and dicyclohexano-18-crown-6 from acid solutions. Russian Journal of Inorganic Chemistry 51(10): 1678-1681 (2016).

18. M. Boltoeva, C. Gaillard, S. Georg, V.K. Karandashev, A.N. Turanov, Speciation of uranium (VI) extracted from acidic nitrate media by TODGA into molecular and ionic solvents. Separation and Purification Technology 203: 11-19 (2018).

19. L. Qiu, Y. Pan, W. Zhang, A. Gong Application of a functionalized ionic liquid extractant tributylmethylammonium dibutyldiglycolamate ([A336][BDGA]) in light rare earth extraction and separation. PLOS ONE 13(8): 1-13 (2018).

20. D. Lutskiy, O. Cheremisina, M. Ponomareva, A. Ignatovich, Determination of the mutual entrainment of the extractant and the aqueous phase in the extraction of rare-earth elements from the technological phosphoric acid solution. Journal of Physics: Conference Series 1399: 1-5 (2019).

21. O.V. Cheremisina, E. Cheremisina, M.A. Ponomareva, A.T. Fedorov, Sorption of rare earth coordination compounds. Journal of Mining Institute 244: 474-481 (2020). 
22. S. Dash, S. Mohanty, ONIOM Study for Selectivity of Extractants for Extraction of Rare Earth Metals. Chemical Engineering \& Technology 41(9): 1697-1705 (2018).

23. R.R. Bontha, R.K. Jyothi, Rare earths extraction, separation, and recovery from phosphoric acid media. Solvent Extraction and Ion Exchange 34(3): 226-240 (2016).

24. L. Wang, Z. Long, X. Huang, Y. Yu Recovery of rare earths from wet-process phosphoric acid. Hydrometallurgy 101(1): $41-47$ (2010).

25. N.N. Hidayah, S.Z. Abidin, Extraction of light, medium and heavy rare-earth elements using synergist extractants developed from ionic liquid and conventional extractants. Comptes Rendus Chimie 22(11-12): 728-744 (2019).

26. N.A. Ismail, A. Hisyam, M.A. Aziz, M.Y. Yunus, Selection of Extractant in Rare Earth Solvent Extraction System: A Review. International Journal of Recent Technology and Engineering (IJRTE) 8(1): 728-743 (2019).

27. K.S. Dhruva, A. Mallavarapu, K.Ya. Kartikey, K.K. Manoj, V. Ravishankar, S. Harvinderpal, Simultaneous recovery of yttrium and uranium using D2EHPA-TBP and DNPPA-TOPO from phosphoric acid. Desalination and Water Treatment 38(1): 292300 (2012).

28. O.V. Cheremisina, V.V. Sergeev, A.T. Fedorov, D.A. Alferova, E.S. Lukyantseva, Study of iron stripping from DEHPA solutions during the process of rare earth metals extraction from phosphoric acid. ARPN Journal of Engineering and Applied Sciences 14(8): 1591-1595 (2019). 